\title{
General Psychiatry Aripiprazole augmentation in treating comorbid bipolar disorder and obsessive-compulsive disorder
}

\author{
Andrea Amerio, ${ }^{1,2}$ Anna Odone ${ }^{3}$
}

To cite: Amerio A, Odone A. Aripiprazole augmentation in treating comorbid bipolar disorder and obsessive-compulsive disorder. General Psychiatry 2018;31:e100007. doi:10.1136/ gpsych-2018-100007

Received 24 August 2018 Revised 16 0ctober 2018 Accepted 22 October 2018
Check for updates

(c) Author(s) (or their employer(s)) 2018. Re-use permitted under CC BY-NC. No commercial re-use. See rights and permissions. Published by BMJ.

${ }^{1}$ Inpatient Mental Health Service, SS. Antonio e Biagio e Cesare Arrigo Hospital, Alessandria, Italy ${ }^{2}$ Mood Disorders Program, Tufts Medical Center, Boston, Massachusetts, USA

${ }^{3}$ School of Medicine, Vita-Salute San Raffaele University, Milan, Italy

Correspondence to Dr Andrea Amerio; andrea.amerio@ospedale.al.it

\section{SUMMARY}

Obsessive-compulsive disorder (OCD) is one of the most difficult additional diagnoses to manage in patients with bipolar disorder (BD) since the gold standard treatment for one disease (antidepressants for OCD) can worsen the other. This case report describes the efficacy of aripiprazole augmentation as maintenance therapy in a young patient with comorbid BD-OCD. Our patient presented complete remission of affective and obsessivecompulsive symptoms with remarkable improvement in social and occupational functioning for 24 months. Adverse drug reactions were not severe enough to result in drug discontinuation. In consideration of the important nosological, clinical and therapeutic implications, future research efforts may lead to more grounded guidelines, which are greatly needed in patients with comorbid BDOCD.

\section{INTRODUCTION}

Obsessive-compulsive disorder (OCD) is one of the most difficult additional diagnoses to manage in patients with bipolar disorder (BD), and the meaning of this comorbidity has not been clarified yet.

The results from our meta-analysis showed higher comorbidity rates in youths $(24.2 \%$, $95 \%$ CI 10.36 to $41.60, \quad \mathrm{n}=345, \quad \mathrm{z}=-9.5$ ) compared with adults $(13.56 \%, 95 \%$ CI 10.4 to $16.25, \mathrm{n}=4539),{ }^{1}$ with the majority of patients who experienced the onset of OCD prior to the onset of BD. ${ }^{2}$ Patients with BD-OCD presented higher prevalence of family history for mood disorders and lower prevalence of family history for OCD than patients without BD-OCD. ${ }^{3}$ Moreover, compared with non-comorbid subjects, patients with BD-OCD have a more episodic course of obsessive-compulsive symptoms, typically with worsening during depression and improvement during mania/hypomania. ${ }^{4}$

BD-OCD comorbidity has important clinical implications: how to treat the comorbidity since the main treatment (serotonin reuptake inhibitors, SRIs) for OCD can worsen BD? ${ }^{5}$
We present the case of a patient with severe BD who developed obsessive-compulsive symptoms during treatment with clozapine.

\section{CASE HISTORY}

The patient is a 25-year-old Caucasian unmarried man with a positive family history of recurrent depression.

When he was 20, he experienced a manic episode with mood-incongruent psychotic features (Diagnostic and Statistical Manual of Mental Disorders, Fifth Edition (DSM-5) criteria) and he was treated with lithium carbonate $900 \mathrm{mg} /$ day and olanzapine 25 $\mathrm{mg}$ /day. Olanzapine was gradually decreased and lithium was continued with mood stabilisation and remission of affective symptoms.

One year later, he developed a severe mixed episode with similar paranoid delusions. His therapy was modified to lithium carbonate $900 \mathrm{mg} /$ day and risperidone $4 \mathrm{mg} /$ day; however, paranoid and affective symptoms were only partially controlled.

Almost 1 year later, manic symptoms and paranoid delusions increased prominently. Risperidone $37.5 \mathrm{mg}$ intramuscular every 2 weeks was added to lithium carbonate 900 $\mathrm{mg}$ /day. Risperidone was stopped because of adverse drug reactions (hyperprolactinemia and weight gain), and his therapy was modified to clozapine $300 \mathrm{mg} /$ day and lithium carbonate $900 \mathrm{mg} /$ day.

However, as clozapine was gradually increased to $450 \mathrm{mg}$ /day, the patient started presenting sexual obsessions with intrusive thoughts that met DSM-5 criteria for OCD. He was treated with paroxetine $30 \mathrm{mg}$ /day without satisfactory control of obsessive-compulsive symptoms.

After 8 weeks, he developed a new manic episode. Paroxetine and clozapine were stopped and the addition of aripiprazole $30 \mathrm{mg} /$ day to lithium carbonate, gradually decreased to $15 \mathrm{mg} /$ day, helped to achieve mood stabilisation and remission 
of obsessive-compulsive symptoms for the following 24 months.

No further hospitalisation was needed and the patient presented a remarkable improvement in social and occupational functioning.

\section{DISCUSSION}

This case report describes the efficacy of aripiprazole augmentation in BD-OCD maintenance therapy. Our patient presented complete remission of obsessive-compulsive symptoms and mood stabilisation without further hospitalisations.

Aripiprazole is an atypical antipsychotic that acts as a partial agonist at the $\mathrm{D}_{2}$ and $5-\mathrm{HT}_{1 \mathrm{~A}}$ receptors, as well as an antagonist at $5-\mathrm{HT}_{2 \mathrm{~A}}$ receptor. Recent studies showed the efficacy of aripiprazole monotherapy or in addition to mood stabilisers in managing acute mania and stabilisation phases in $\mathrm{BD}$, and in addition to SRIs in refractory OCD. Futhermore, there is evidence that aripiprazole augmentation to mood stabilisers, even at low doses, is also effective in patients with BD-OCD comorbidity. ${ }^{6}$

In our case, positive family history for affective disorders, improvement of affective and obsessive-compulsive symptoms with mood stabilisers and atypical antipsychotics, and manic switch induced by antidepressant, support the hypothesis of an underlying OCD comorbidity unmasked by the use of clozapine to manage treatment-resistant $\mathrm{BD}$.

The results from a recent systematic review showed that mood stabilisation should be the first objective in patients with apparent BD-OCD, as opposed to immediate treatment with SRIs. Addition of SRI agents seems unnecessary in most cases, although it may be needed in refractory OCD. ${ }^{7}$

Progress in this area would serve to shed light on the best clinical management of BD-OCD comorbidity. In consideration of the important nosological, clinical and therapeutic implications, future research efforts may lead to more grounded guidelines, which are greatly needed in patients with comorbid BD-OCD.

Contributors AA has contributed to data acquisition. $\mathrm{AA}$ and $\mathrm{AO}$ have been involved in data interpretation and drafting the manuscript. Our manuscript has been approved by all authors.

Funding The authors have not declared a specific grant for this research from any funding agency in the public, commercial or not-for-profit sectors.

Competing interests None declared.

Patient consent Obtained.

Ethics approval Comitato Etico Azienda USL di Parma.

Provenance and peer review Not commissioned; externally peer reviewed.

Open access This is an open access article distributed in accordance with the Creative Commons Attribution Non Commercial (CC BY-NC 4.0) license, which permits others to distribute, remix, adapt, build upon this work non-commercially, and license their derivative works on different terms, provided the original work is properly cited and the use is non-commercial. See: http://creativecommons.org/ licenses/by-nc/4.0

\section{REFERENCES}

1. Amerio A, Stubbs B, Odone A, et al. The prevalence and predictors of comorbid bipolar disorder and obsessive-compulsive disorder: a systematic review and meta-analysis. J Affect Disord 2015;186:99-109.

2. Tonna M, Amerio A, Odone A, et al. Comorbid bipolar disorder and obsessive-compulsive disorder: which came first? Aust N Z J Psychiatry 2016;50:695-8.

3. Amerio A, Tonna M, Odone A, et al. Heredity in comorbid bipolar disorder and obsessive-compulsive disorder patients. Shanghai Arch Psychiatry 2015;27:307-10.

4. Amerio A, Tonna M, Odone A, et al. Course of illness in comorbid bipolar disorder and obsessive-compulsive disorder patients. Asian $J$ Psychiatr 2016;20:12-14.

5. Pacchiarotti I, Bond DJ, Baldessarini RJ, et al. The International Society for Bipolar Disorders (ISBD) task force report on antidepressant use in bipolar disorders. Am J Psychiatry 2013;170:1249-62.

6. Lai J, Lu Q, Zhang P, et al. Aripiprazole augmentation in managing comorbid obsessive-compulsive disorder and bipolar disorder: a case with suicidal attempts. Neuropsychiatr Dis Treat 2017;13:87-90.

7. Amerio A, Odone A, Marchesi C, et al. Treatment of comorbid bipolar disorder and obsessive-compulsive disorder: a systematic review. $J$ Affect Disord 2014;166:258-63.

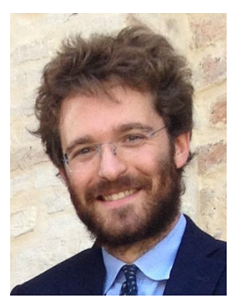

Andrea Amerio, MD, PhD, is a psychiatrist at the Department of Mental Health of Alessandria (Italy). Since January 2013 he has been a research fellow at the Mood Disorders Program, Tufts University - Boston, MA (USA). Supervised by Professor Ghaemi SN his research focuses on psychiatric comorbidities in bipolar disorders. 